\title{
Significance of the site of origin of pancreatic exocrine adenocarcinoma
}

\author{
TG ALLEN-MERSH
}

From the Department of Surgery, Charing Cross Hospital Medical School, London W6 8RF

SUMMARY The pancreatic head and neck constitute less than half (mean $46 \pm 5 \%$ ) of the whole pancreas. There is no difference in the concentration of ductal epithelium between the head and the body of the pancreas. The preponderance of pancreatic exocrine tumours which arise in the head of the pancreas compared to the body is not, therefore, due to a larger number of cells at risk in the pancreatic head. This suggests that there is a greater risk of exocrine adenocarcinoma developing from the cells within the head of the pancreas than in those within the body of the pancreas.

Studies of the distribution of the site of origin of pancreatic ductal-adenocarcinoma, carried out at necropsy, suggest that $60 \%$ of these tumours arise in the head or neck of the pancreas (Table). This apparently uneven distribution may be an important clue to the pathogenesis of this condition and it has prompted Wynder ${ }^{6}$ to suggest that it could be produced by pancreatic ductal reflux of carcinogens from the duodenum. However, Bouchier ${ }^{7}$ has pointed out that more tumours may appear to arise from the pancreatic head and neck because there is more pancreatic tissue in these areas than in the body and tail of the pancreas. This view has been supported by studies of experimental nitrosamine-induced pancreatic tumours in the hamster. ${ }^{8}$ In this animal model of the human disease, the distribution of pancreatic tumours corresponds to the distribution of pancreatic tissue between the three lobes of the hamster pancreas. The greatest incidence of tumour is in the largest splenic lobe.

Necropsy surveys have consistently suggested that a preponderance of pancreatic carcinomas arise in the head and neck of the pancreas

\begin{tabular}{|c|c|c|c|c|}
\hline \multirow{2}{*}{$\begin{array}{l}\text { No of } \\
\text { cases }\end{array}$} & \multicolumn{3}{|c|}{$\%$ distribution of site of origin } & \multirow[t]{2}{*}{ Reference } \\
\hline & $\begin{array}{l}\text { Head } \\
\text { and } \\
\text { neck }\end{array}$ & $\begin{array}{l}\text { Body } \\
\text { and or } \\
\text { tail }\end{array}$ & $\begin{array}{l}\text { Multiple } \\
\text { or diffuse }\end{array}$ & \\
\hline 57 & $61 \cdot 4$ & $5 \cdot 2$ & $33 \cdot 3$ & Mirallie C $(1893)^{1}$ \\
\hline 50 & 56 & 38 & 6 & Duff GL (1939) ${ }^{2}$ \\
\hline 609 & $59 \cdot 1$ & $25 \cdot 6$ & $15 \cdot 3$ & Bell ET $(1957)^{3}$ \\
\hline 68 & $70 \cdot 5$ & 10.9 & $19 \cdot 1$ & Parkash O (1972) \\
\hline 380 & 61 & 18 & 21 & $\begin{array}{l}\text { Cubilla A, Fitzgerald PJ } \\
\quad(1978)^{5}\end{array}$ \\
\hline
\end{tabular}

Accepted for publication 24 September 1981
It is not clear, therefore, whether in man this uneven distribution of pancreatic tumours is due to a greater risk of neoplastic change in the ductal epithelium of the pancreatic head and neck or whether the risk of neoplastic change is the same but there is more ductal epithelium in the head and neck of the pancreas than in the body and tail. The purpose of this study was to discover the relative distribution in man of pancreatic tissue, in particular ductal epithelium, between the head and neck and the body and tail of the pancreas.

\section{Material and methods}

Pancreas was obtained at necropsy less than $48 \mathrm{~h}$ after death from non-pancreatic disease. After fixation in $10 \%$ formalin for five days it was sliced throughout its length at $1 \mathrm{~cm}$ intervals in the sagittal plane. The neck of the pancreas is the region where the uncinate process and superior mesenteric vein are posterior relations of the pancreas ${ }^{9}$ and this could be accurately identified by examination of the serial sagittal slices taken through this region. The weight of those slices making up the head and neck, and those from the body and tail of the pancreas were noted. Seventy-seven pancreases were examined.

Tissue removed from the head and from the body of eight pancreases was processed and stained by haematoxylin and eosin. Using a computerised microscope morphometer (Cambridge Electronic Design Ltd) the lengths of the perimeters of the inter and intralobular, and intercalary ducts seen in a $958141 \mu \mathrm{m}^{2}$ field were measured; 25 fields in each section, a total area of $23.95 \mathrm{~mm}^{2}$ per section were measured. The sum of the duct perimeters 
measured in each section, and the frequency of occurrence of ducts by perimeter size were compared between sections taken from the head of the pancreas and those taken from the body.

\section{Results}

The mean weight of the head and neck of the pancreas (38 g) was significantly less $(t=6 \cdot 23$, $\mathrm{p}<0.001)$ than the mean weight of the tissue from the body and tail $(44 \mathrm{~g})$. The proportion, expressed as a percentage, of the total pancreatic weight which is contributed by the head and neck of the pancreas (mean $46 \pm 5 \%$ ) is shown in Fig. 1 for the specimens which were examined.

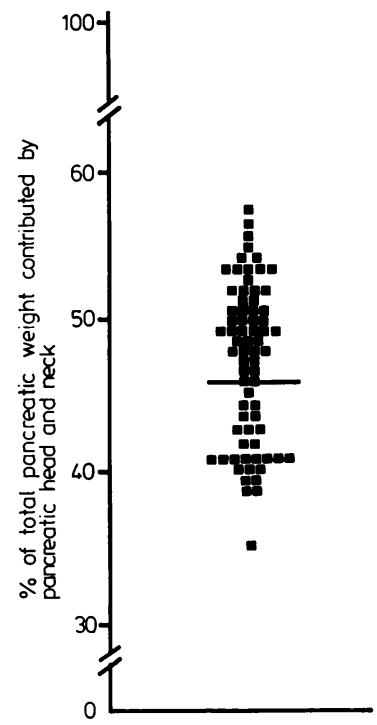

Fig. 1 The proportion of the total pancreatic weight (expressed as a percentage) which is contributed by the head and neck of the pancreas is shown for the specimens which were examined. The mean value is $46 \%$ and in only one specimen did the value approach $60 \%$ which is the proportion of tumours arising from the head and neck of the pancreas.

There was no significant difference in either the total perimeter of ductal epithelium measured per unit area (Fig. 2) or in the frequency of occurrence of ducts by perimeter size (Fig. 3 ) between the head and the body of the pancreas.

\section{Discussion}

The pancreatic head and neck constitute a mean of $46 \%$ of the total pancreatic weight, but are the site of origin of about $60 \%$ of pancreatic exocrine

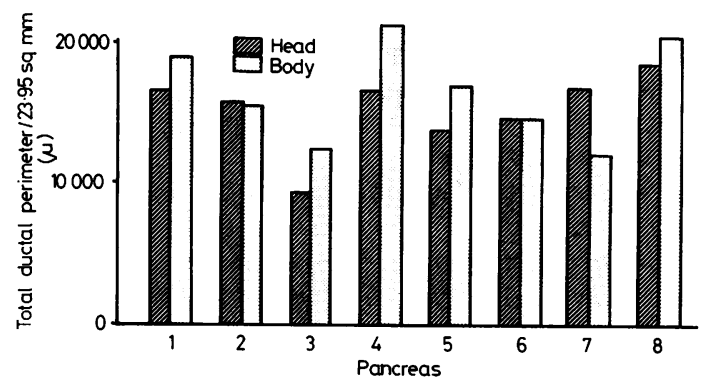

Fig. 2 The total ductal perimeter $(\mu \mathrm{m})$ measured in an area of $23.95 \mathrm{sq} \mathrm{mm}$ taken from sections of the head compared to that from the same area of sections from the body of the same pancreas. There is no significant difference between the amount measured in each area from the same pancreas.

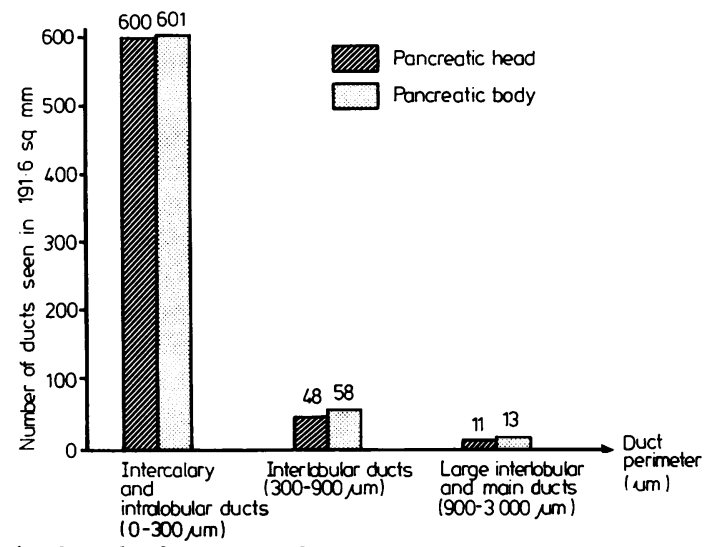

Fig. 3 The frequency of ducts, according to their perimeter size, measured in an area of $191.6 \mathrm{sq} \mathrm{mm}$. There are fewer ducts as their perimeter size increases, but the number found in tissue from the head of the pancreas is similar to that in tissue from the body.

tumours. This difference is not explained by a change in the concentration of ductal epithelium or a difference in the incidence of ducts of a particular size between the pancreatic head and body. Differences between the amount of fat contained within the head and the body of the pancreas might influence these proportions. The head of the neonatal pancreas contains areas in which there is variation in the amount of intralobular fat present. 10

However these differences in intralobular fat are small (of the order of $1-2 \%$ of the total pancreatic volume) and the mean for all areas of the head could not differ from the mean value for the pancreatic body by more than $1 \%$ of the total pancreatic volume. Any difference of this size would not have a significant effect on the findings described herein. Thus the incidence of pancreatic tumours in relation 
to the amount of pancreas from which they arise is about $\times 1.8$ greater in the head and neck than in the body and tail of the pancreas.

Bates $^{11}$ has suggested that this increase could be due to earlier diagnosis of tumours in the head of the pancreas which would therefore be more localised than tumours of the body of the pancreas which often do not produce symptoms until the disease is more widespread. However, the estimate of $60 \%$ of pancreatic tumours originating from the head of the pancreas does not include diffuse tumours of the pancreas as it relates only to those localised at the time of necropsy to the pancreatic head. In fact, evidence from experimental pancreatic tumours in the rabbit suggests that a proportion of diffuse pancreatic tumours may originate in the head.12 In this animal model those tumours originating in the head of the pancreas are more likely to spread to the tail because duct obstruction in the head with accompanying stasis predisposes to tumour spread towards the tail.

Willis ${ }^{13}$ has proposed that many cancers of the retropancreatic common bile duct are incorrectly ascribed to an origin from the pancreas thus spuriously increasing the incidence of tumours in the pancreatic head. In a typical necropsy survey Miller, Baggenstoss and Comfort ${ }^{14}$ found that the average diameter of a tumour of the head of the pancreas at necropsy was $4 \cdot 2 \mathrm{~cm}$. A tumour of the common bile duct would produce obstructive jaundice at a very much smaller size than this and would bean improbable source for such a large tumour which has the clinical reputation for being unresectable by the time jaundice has developed. It is more likely that tumours of the retropancreatic bile duct would be included in the category of "ampullary tumours" than pancreatic tumours.

There appears, therefore, to be a real increase in the risk of adenocarcinoma developing in the head of the pancreas compared to the body. The reason for this is not clear. It may be due to the effect of duodenopancreatic reflux of carcinogens in bile ${ }^{15}$ or gastroduodenal juice, ${ }^{16}$ or it may be due to an alteration in the pancreatic juice, as it passes along the pancreatic duct, affecting either the concentration or the activation of a pancreatic carcinogen so that it exerts a greater effect on the head than on the body of the pancreas. Although its significance is not understood this uneven distribution does appear to be one of the few clues to those factors which affect the development of carcinoma in the human pancreas.
I am indebted to the Department of Histopathology for their generous co-operation in the provision of specimens and to the Department of Experimental Pathology, Charing Cross Hospital Medical School for making available the computerised microscope morphometer. This work was supported by a grant from the North West Thames Regional Research Committee.

\section{References}

${ }^{1}$ Mirallie C. Cancer primitif du pancreas. Gaz d'hop Par $1893 ; 66: 889-98$.

${ }^{2}$ Duff GL. The clinical and pathological features of carcinoma of the body and tail of the pancreas. Bulletin of the Johns Hopkins Hospital 1939;65:69-101.

${ }^{3}$ Bell ET. Carcinoma of the pancreas. I. A clinical and pathological study of 609 necropsied cases. Am J Pathol 1957;33:499-511.

${ }^{4}$ Parkash $\mathrm{O}$. On the statistical and clinical evaluation of carcinoma of the pancreas. Digestion 1972;6:152-64.

${ }^{5}$ Cubilla A, Fitzgerald PJ. Pancreas cancer. I. Duct adenocarcinoma. Pathol Annu 1978;13:241-89.

${ }^{6}$ Wynder EL, Mabuchi K, Maruchi N, Fortner JG. Epidemiology of cancer of the pancreas. $J$ Natl Cancer Inst 1973;50:645-67.

${ }^{7}$ Bouchier IAD. Cancer of the pancreas. Br Med J 1968; 3:169-71.

${ }^{8}$ Pour P, Donnelly T. Effect of cholecystduodenostomy and choledochostomy in pancreatic carcinogenesis. Cancer Res 1978;38:2048-51.

9 Williams PL, Warwick R. In: Grays Anatomy 36th ed. Edinburgh: Churchill Livingstone,1980;8:1370.

${ }^{10}$ Orci L, Stefan Y, Malaisse-Lagae F, Perrelet A, Patel Y. Pancreatic fat. $N$ Engl J Med 1979;30:1292.

${ }^{11}$ Bates RR. Chemical carcinogenesis and the pancreas. J Surg Oncol 1975;7:143-9.

${ }^{12}$ Nakase A, Koizumi T, Fujita N, Ono H, Matsumoto Y, Honjo J. Studies of the growth and infiltration of experimental tumours of the pancreas in rabbits. Am J Surg 1977;133:590-2.

${ }^{13}$ Willis RA. Pathology of tumours. 4th ed. London: Butterworths, 1967:446.

14 Miller JR, Baggenstoss AH, Comfort MW. Carcinoma of the pancreas. Effect of histological type and grade of malignancy on its behaviour. Cancer 1951;4:233-41.

${ }^{15}$ Allen-Mersh TG, Marshall CE, Smith PLR, Walters CH. Nitrosamines in bile. Lancet 1981 ; ; :835-6.

${ }^{16}$ Schlag $P$, Bockler $R$, Ulrich $H$, Peter $M$, Merkle $P$, Herfath CL. Are nitrite and $\mathrm{N}$-nitroso compounds in gastric juice risk factors for carcinoma in the operated stomach. Lancet 1980;i:727-9.

Requests for reprints to: Dr TG Allen-Mersh, Senior Surgical Registrar, Whipps Cross Hospital, London E11, England. 